\title{
Student and Teacher De-Motivation in SLA
}

\author{
Hui Yan \\ School of Foreign Languages \\ Qingdao University of Science and Technology \\ Qingdao 266061, Shandong, China \\ E-mail: magyan@sohu.com
}

\begin{abstract}
With a brief introduction of the definitions of de-motivation, this article reviews present research on student de-motivation, analyzes the teacher motivation from the macro-contexts and micro-contexts, and puts forward suggestions in getting rid of de-motivation.
\end{abstract}

Keywords: De-motivation, Macro-contexts, Micro-contexts

\section{Introduction}

Present research on motivation has focused mainly on introducing positive motives, with little attention paid to de-motivation studies, which " in spite of their great significance, have received very little attention either in mainstream psychology or L2 research" (Dornyei, 2005: 3). Though de-motivation is a very complex issue, it is very helpful to study de-motivation and de-motives, thus shedding light on the motivation research.

\section{De-motivation}

\subsection{Definition of de-motivation}

Dornyei (2005: 143) defines de-motivation as "specific external forces that reduce or diminish the motivational basis of a behavioral intention or an ongoing action". Deci and Ryan (1985) uses a similar term "amotivation", which means " the relative absence of motivation that is not caused by a lack of initial interest but rather by the individual's experiencing feelings of incompetence and helplessness when faced with the activity." Though both of these terms concern lack of motivation, they differ in that amotivation is related to general outcomes expectations that are unrealistic for some reason whereas de-motivation concern specific external causes. A de-motivated learner is someone who was once motivated but has lost his or her commitment /interest for some reason. De-motives are the negative counterparts of motives. Some de-motives can lead to general amotivation regarding the particular activity whereas others may have no effect on amotivation as long as the negative external motives cease to exist. Dornyei points out that de-motivation does not mean that all the positive influences that originally made up the motivational basis of a behavior have been got rid of. It only means that a strong negative factor restrains the present motivation with some other positive motives still remain ready to be activated. For example, a Chinese student may lose his interest in learning English as soon as he passed the CET-4.

\subsection{Research on De-motivation}

\subsubsection{Christophel and Gorham's study}

Christophel and Gorham $(1995,1992)$ initiated two different investigations of de-motivation with both qualitative and quantitative techniques. The results indicate that most subjects attribute de-motivation to what the teacher had done or had been responsible for. Gorham and Christophel (1992) also summarized a rank of order of the frequency of the various demotives, with first five categories as dissatisfaction with grading and assignments; the teacher being boring, bored, unorganized and unprepared; the dislike of the subject area; the inferior organization of the teaching material and the teacher being unapproachable, self-centered, biased, condescending and insulting. This rank offers a initiative insight into the true nature of teacher's role in de-motivation.

\subsubsection{Oxford's studies}

Oxford (1998) carried out an investigation on approximately 250 American students (both in high schools and universities) about their learning experiences over a period of five years. During this investigation, students are expected to comment on a variety of topics such as to "Describe a situation in which you experienced conflict with a 
teacher" and "Talk about a classroom in which you felt uncomfortable". Four types of de-motivation factors are discovered: the teacher's personal relationship with the students, the teacher's attitude towards the course or the material, style conflicts between teachers and students and the nature of the classroom activities. From the analyses it is clear that his studies centers on the classroom learning and teacher's demotivating roles. Many demotives were found such as the teacher's lack of caring or patronage/favoritism; the teacher's lack of enthusiasm and sloppy management towards the course or the material, their conflicts about the degree of closure or seriousness of the class and the amount of irrelevance and repetitiveness. This research is of vital importance because it reveals a fact that most teachers will easily attribute students de-motivation to various reasons including psychological, attitudinal, social, historical and even geographical reasons without realizing the potential de-motiving roles of themselves.

\subsubsection{Chambers' questionnaires}

Chambers (1993) conducted a questionnaire to 191 pupils of 4 schools in Leeds in Britain on their explanations about de-motivation and a questionnaire to 7 teachers about the main characteristics of the demotived pupils. The teachers' interpretations are quite coherent. They consider that demotived students make no effort to learn, lack belief in their own capabilities, demonstrate laziness and are unwilling to learn.

Students' understandings, however, vary from person to person. Some blame their teachers because teachers frequently criticize students and explain things insufficiently. Teachers use old-fashioned teaching materials and inferior equipment, thus losing their students and being ignorant of it. Others accuse the number of students in the class and language room facilities. In sum, Chambers finds that students believe that de-motivation originates from different sources: home, previous language learning experience, the perception of the teacher and students' low self-esteem, etc. It's obvious that teachers' understandings are very different from students' perceptions. Therefore, Chambers concludes that "seeking the help of pupils might be a good place to start" (1999:16), thereby stating the importance of communication and cooperation between teachers and students.

\subsubsection{Ushioda's qualitative investigation}

Ushioda (1998) administered a two-stage interview of 20 Irish learners of French. They were asked to identify what they found to be de-motivating in their L2 learning experiences. Evidently, those learners attribute positive L2 outcomes to personal ability or other internal factors whereas attribute negative L2 outcomes or lack of success to external factors. Their answers "overwhelmingly targeted negative aspects of the institutionalized learning framework, rather than personal factors such as falling grades or negative self-perceptions of ability" (1998: 86). Ushioda welcomes this finding by holding that in so doing these learners will be better able to develop self-motivation and learning autonomy, offering a different aspect for motivation research.

\subsubsection{Dornyei's study}

Dornyei (1998) started a qualitative analysis by conducting structured long interviews in 10 to 30 minutes of 50 secondary school pupils who were studying either English or German as a foreign language. Nevertheless, in his study the participants were not of cross-sectional students but were those who had been identified by their teachers or peers as being particularly de-motivated. He identified 9 types of de-motivating factors: the teacher (personality, commitment, competence, telling method), inadequate school facilities (group is too big or not the right level; frequent change of teachers), reduced self-confidence (experience of failure or lack of success), negative attitudes towards the L2, compulsory nature of L2 study, interference of another foreign language being studied, negative attitude towards L2 community, attitudes of group members and coursebook used in the language class. The compulsory nature of L2 studies and the interference of a L3 were first discovered in this study. The negative effect of the compulsory nature of L2 learning is obviously related to the lack of learner autonomy and lack of self-determination. This is especially true in China, where most Chinese were forced to learn English as a second language whether they are students or working people. No matter whatever school they'd like to attend they have to meet the corresponding requirements for English. No matter whatever job they are doing, say professors of Chinese, they must pass relevant English tests in order to win chances of promotion. As a result, the corresponding pressure and rejection will be enormous, leading easily to de-motivation. The interference of L3 is also evident when learners are learning two languages at the same time. Among 9 factors teacher factor ranks first. The teacher's personality commitment to teaching, attention paid to the students, competence, teaching method, style and rapport with students can have a direct impact on students de-motivation. Students also attribute their lack of confidence to teacher's indirect negative influence, such as rigid classroom management, their perception of teacher's strict marking. Such results were consistent with previous studies. Therefore, it is of vital importance to analyze the teacher factor in order to find possible solutions to de-motivation.

\subsection{Teacher motivation}

There are two levels of contextual influences on teacher motivation: macro-contexts and micro-contexts. Macro-contextual influences refer to "the general work echoes prevalent at the social level". They include anticipation for intrinsic rewards such as "to educate people, to impart knowledge and values, and to advance a community or a 
whole nation" and extrinsic rewards such as "high salaries and social recognition" In this respect teaching is exposed to external influences from every corner of the society, including politicians, parents and media.

Micro-contextual influences are more closely related to "the organizational climate of the particular institution in which the teacher works and the characteristics of the immediate teaching environment, that is, the classroom and the learner group". The specific factors include the school's general climate and the existing school norms; the class size, the school resources and facilities; the standard activity structure within the institution; collegial relations; the definition of the teacher's role by colleagues and authorities; general expectations regarding student potential; the school's reward contingencies and feedback system; the school's leadership and decision-making structure. In short, five general de-motivating factors of teacher lead to de-motivation: stress, restricted autonomy, insufficient self-efficacy, lack of intellectual challenge and inadequate career structure.

On the one hand, we should encourage teacher motivation; on the other, we should understand the relationship between teacher motivation and student motivation and make the best use of it. Deci $(1997,68)$ states, the relationship between students and faculty is an "interactive one that can be either positive or negatively synergistic." Students affect the teachers' motivation and behavior just as teachers affect the students'. But it is teacher's task to realize that students' lack of enthusiasm can equally affect them negatively, thus engendering in students "the enthusiasm that facilitates a positive rather than a negative cycle".

In short, effective teachers are not necessarily the ones who are successful in the business of transferring cognitive information. In fact, the positive impact of good teachers is due to the strength of their commitment towards the subject matter and the ability to instill in students a similar willingness to pursue knowledge. As Csikszentmihalyi $(1997,72)$ summarizes, "the best way to get students to believe that it makes sense to pursue knowledge is to believe in it oneself"

\subsection{Solutions}

We should bear in mind that there are abundant varieties of effective motivational strategies. Since it is impossible to list all, it is advisable to name only a small number of "core strategies", making it possible for teachers and students to understand and follow.

In order to reduce student de-motivation, Williams and Burden (1997) put forward a list of suggestions for motivating language learners:

1. Recognize the complexity of motivation.

2. Be aware of both initiating and sustaining motivation.

3. Discuss with the learners why they are carrying out activities.

4. Involve learners in making decisions related to learning the language.

5. Involve learners in setting language-learning goals.

6. Recognize people as individuals.

7. Build up individuals' beliefs in themselves.

8. Develop internal beliefs.

9. Help to move towards a mastery-oriented style.

10. Enhance intrinsic motivation.

11. Build up a supportive learning environment.

12. Give feedback that is informational.

(Williams and Burden, 1997:141-2)

Apart from this list, Dornyei and Csizer (1998: 215) developed a set of macro-strategies making the concept of motivating learners more teacher-friendly, entitled the "Ten commandments for motivating language learners".

1. Set a personal example with your own behavior.

2. Create a pleasant, relaxed atmosphere in the classroom.

3. Present the task properly.

4. Develop a good relationship with the learners.

5. Increase the learner's linguistic self-confidence.

6. Make the language classes more interesting.

7. Promote learner autonomy.

8. Personalize the learning process. 
9. Increase the learner's goal-orientedness.

10. Familiarize learners with the target language culture.

(Dornyei and Csizer, 1998: 215)

To diminish teacher de-motivation, Corno and Kanfer (1993:312-13) put forward a set of self-motivating strategies for teachers:

1. Reflect immediately after a lesson on how it went and make mental notes on what to do differently next time.

2. Imagine being named teacher of the year and how satisfied that would make you.

3. Observe other teacher as a learning tool.

4. Marshal inner resources and remember you've been through more than this and made it.

5. Analyze why you feel so anxious about aspects of your work and think through ways to overcome these feelings.

6. Embellish your teaching- keep changing what you do- so it's more interesting for you to teach it again.

7. Rearrange the classroom layout for maximal attention from students.

8. Call teacher study groups to resolve problems cooperatively.

The above sets of strategies serve as guidelines in reducing student and teacher de-motivation in classroom learning activities. Although these motivational strategies had been welcomed by students and teachers, the complexity of motivation and human behaviors only testify that there are so many other different ways to get rid of student and teacher de-motivation.

\section{Conclusion}

De-motivation is a frequent and common phenomenon in L2 learning. After the literature review of student and teacher de-motivation, we should realize that these previous studies only reveal the complexity of this issue, further indicating the due responsibility of teachers. The results of previous studies have no only discovered some of the true nature of de-motivation but also pointed out some effective strategies of reducing de-motivation, leading to the vast fields for future research.

\section{References}

Chambers, G.N. (1993). Taking the "de" out of de-motivation. Language Learning Journal, 7, 13-16.

Christophel, D. M. \& Gorham J. (1995). A test-retest analysis of student motivation, teacher immediacy and perceived sources of motivation and de-motivation in college classes. Communication Education, 44, 292-306.

Corno, L \& Kanfer R. (1993). The role of volition in learning and performance. Review of Research in Education, 14, $312-13$.

Deci, E. L. \& Ryan, R. M.(1985). Intrinsic motivation and self-determination in human behaviour. Plenum, New York.

Dornyei, Z. (1998). De-motivation on foreign language learning. Paper presented at the TESOL'98 Congress, Seattle, WA, March.

Dornyei, Z. (2005). Teaching and researching motivation. Beijing: Foreign Language Teaching and Research Press.

Gorham, J. \& Christophel, D. M. (1992). Students' perception of teacher behaviors as motivating and demotivating factors in college classes. Communication Quarterly, 40, 239-52.

Oxford, R.L. (1998). The unraveling tapestry: Teacher and course characteristics associated with de-motivation in the language classroom. De-motivation in foreign language learning. Paper presented at the TESOL'98 Congress, Seattle, WA, March.

Ushioda, E. (1998). Effective motivation thinking: A cognitive theoretical approach to the study of language learning motivation. In Soler E. A and Espurs V.C (eds) Current issues in English Language methodology. Plymouth: University of Plymouth, pp 39-50.

Williams, M. \& Burden, R. (1997). Psychology of language teachers. Cambridge: Cambridge University Press. 